\title{
Sistem Penjejak Posisi Kendaraan Bermotor Berbasis GPS Melalui Media SMS \\ Budianto $^{1}$, M. Taufiq Tamam ${ }^{2}$, Latiful Hayat ${ }^{3}$ \\ Program Studi S1 Teknik Elektro, Universitas Muhammadiyah Purwokerto \\ Fakultas Teknik dan Sains, Universitas Muhammadiyah Purwokerto
}

\section{Informasi Makalah}

Dikirim, 8 Mei 2019

Direvisi, 1 Juli 2019

Diterima,

\section{Kata Kunci:}

SMS(Short Message Service)

GPS(Global Positioning

System)

Mikrokontroler

Sistem keamanan kendaraan bermotor.

\section{Keyword:}

SMS(Short Message Service),

GPS(Global Positioning System)

Microcontroller

Motor vehicle security system.

\begin{abstract}
INTISARI
Ketika tindak kejahatan yang semakin meningkat, terutama dalam kasus pencurian kendaraan bermotor. Solusi yang dilakukan oleh pemilik kendaraan bermotor biasanya hanya menggunakan kunci ganda. Pencuri dapat membuat duplikat kunci kendaraan sehingga pencuri dengan santai bisa untuk mengambilnya.Dalam perkembangan teknologi saat ini, teknologi telepon seluler telah berubah menjadi perangkat multifungsi. Dengan memanfaatkan SMS(Short Message Service) dapat mengontrol sistem keamanan kendaraan bermotor menggunakan Mikrokontroler AT-Mega 328, serta modul GPS SIMCOM SIM908 untuk bisa mengetahui lokasi kendaraan tersebut berada. Dengan teknologi yang semakin canggih sekarang diharapkan kejahatan, terutama pencurian kendaraan dapat dikurangi. Dengan sistem keamanan kendaraan bermotor menggunakan GPS berbasis media SMS dapat memberikan keamanan lebih kepada pemilik kendaraan, karena pemilik kendaraan dapat mengetehui keberadaan kendaraanya jika terjadi suatu pencurian
\end{abstract}

\section{Korespondensi Penulis:}

Budianto

Program Studi S1 Teknik Elektro

Universitas Muhammadiyah Purwokerto

Jl. Raya Dukuh Waluh Purwokerto, 53182

Email: budiderta@gmail.com

\section{PENDAHULUAN}

Semakin kerasnya kehidupan menyebabkan banyak orang menjadi gelap mata. Mereka menghalalkan segala cara untuk memenuhi kebutuhan hidup mereka demi mempertahankan kelangsungan hidupnya. Salah satu tindakan kriminal yang baru maraknya di era sekarang adalah tindakan kriminal pencurian kendaraan bermotor. Dengan meningkatnya tindak kriminalitas, khususnya pencurian kendaraan bermotor bukanlah hal 
yang mengherankan apabila semakin hari manusia menginginkan suatu sistem keamanan kendaraan bermotor yang modern. Solusi yang biasa dilakukan oleh pemilik kendaraan bermotor hanya dengan memakai kunci (gembok). Seiring dengan perkembangan teknologi yang sangat pesat, telepon seluler merupakan salah satu teknologi yang sangat digandrungi masyarakat. Dengan memiliki telepon seluler, melalui vitur SMS (Short Message Service) yang ada didalamnya dan memanfaatkan satelit GPS dapat digunakan sebagai alat pengaman pada kendaraan bermotor. Berdasarkan permasalahan di atas, maka akan dibuat alat dengan judul "Sistem Penjejak Posisi Kendaraan Bermotor Berbasis GPS (Global Positioning system) Melalui Media SMS (Short Message Service)". Topik yang perlu diperhatikan dalam penelitiah ini adalah:Masalah yang muncul dalam pengerjaan alat adalah:

1. Bagaimana cara membuat program untuk menghubungkan SMS dengan modul GPS lalu menampilkannya di Google Maps.

2. Bagaimana merancang modul GPS SIM908 agar terhubung dengan sistem minimum.

3. Bagaimana cara menganalisa sistem dari keseluruhan alat GPS tracker yang telah dibuat.

Agar sistem ini lebih spesifik dan terarah, maka pembahasan masalah dalam program ini memiliki batasanbatasan sebagai berikut:

1. Menggunakan mikrokontroler AT-Mega 328, serta bahasa pemrograman yang digunakan pada alat ini adalah Bahasa C.

2. Menggunakan modul GPS Itead SIM908 sebagai penghubung ke satelit dengan media SMS sebagai masukannya.

3. Aplikasi Google Maps digunakan untuk menampilkan posisi kendaraan tersebut.

\section{METODE PENELITIAN}

Metode adalah sebuah sistem atau cara yang digunakan untuk memperoleh data yang baik dalam penyusunan artikel, diperlukan banyak referensi yang berasal dari berbagai sumber untuk dijadikan data. Data tersebut diperoleh dengan cara:

1. Observasi atau pengamatan

Pengumpulan data dilakukan dengan cara mengadakan pengamatan secara langsung terhadap objek.

2. Interview atau wawancara

Pengumpulan data dilakukan dengan cara mencari informasi segala sesuatu yang berhubungan dengan objek.

3. Studi pustaka

Aktivitas mempelajari teori-teori yang berhubungan dengan data yang akan disusun dalam laporan dengan cara membaca buku-buku atau literatur-literatur yang berkaitan dengan isi laporan artikel

\section{HASIL DAN PEMBAHASAN}

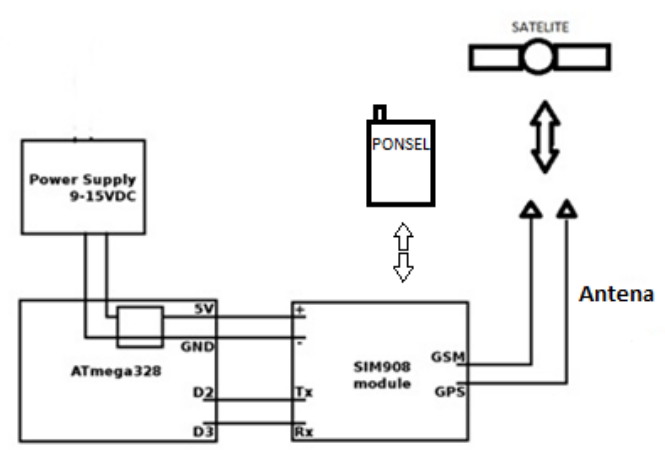

Gambar 3.1 Diagram blok system

Halaman Web JRRE : http://jurnalnasional.ump.ac.id/index.php/JRRE 
Diagram blok sistem secara umum terdapat 3 bagian, yaitu :

1. Blok input terdiri atas power supply, SIM908 module, satelit, dan telepon seluler (mengirim SMS).

2. Blok output terdiri atas telepon seluler (menerima SMS) dan menampilkan di Google Maps.

3. Blok kontrol terdiri atas AT-Mega 328.

Bagian-bagian tersebut terhubung menjadi satu agar alat dapat berjalan dengan baik. Mikrokontroler mendapat supply 9-15 VDC atau 220 AC, kemudian diturunkan menjadi 5V. Telepon seluler sebagai media input maupun output sebagai pengirim juga penerima SMS kemudian bisa menampilkan pada aplikasi Google Maps. Modul GPS SIM908 sebagai penghubung ke satelit. Sedangkan bagian pemproses utama sekaligus pengendali utama adalah Mikrokontroller AT-Mega 328.

\subsection{Cara Kerja Rangkaian Arduino UNO R3}

Pusat pengendali dan proses dari sistem penjejak posisi kendaraan pada penelitian ini berupa Arduino Uno R3. Mikrokontroler melakukan fungsinya sesuai dengan program yang sudah ditentukan dan dirancang sedemikian hingga menjadi suatu sistem yang sesuai dengan apa yang diinginkan

Arduino Uno R3 memiliki 14 buah pin, pada sistem penjejak posisi kendaraan ini hanya menggunakan beberapa pin mikrokontroler sesuai fungsi dan kegunaannya. Berikut ini adalah penjelasan konfigurasi pin yang digunakan :

1. $\mathrm{V}$ in digunakan untuk mengalirkan sumber tegangan ke arduino uno ketika menggunakan sumber daya eksternal (selain dari koneksi USB atau sumber daya yang teregulasi lainnya). Sumber tegangan juga dapat disediakan melalui pin ini jika sumber daya yang digunakan untuk Arduino Uno dialirkan melalui soket power

2. Pin reset digunakan untuk mengendalikan pin reset pada mikrokontroler.

3. PD2 digunakan sebagai jalur penerima data serial (Tx).

4. PD3 digunakan sebagai jalur pengirim data serial $(\mathrm{Rx})$.

5. PD4 dihubungkan sebagai power pada modul.

\subsection{Perancangan Perangkat Lunak}

Pembuatan program pada Tugas Akhir ini menggunakan Arduino 1.0.6 sebagai software compiler. Sistem yang telah dibentuk dengan sebuah mikrokontroler AT-Mega 328 sebagai pusat pengendali sistem, membutuhkan program agar sistem dapat berjalan sesuai dengan yang telah dirancang. Diagram alur yang telah dibuat digunakan sebagai acuan dalam pembuatan program. Dalam menerjemahkan diagram alur menjadi suatu sistem, dibutuhkan bahasa pemrograman, salah satunya bahasa C. pemilihan bahasa pemrograman ini didasarkan pada kemudahan dalam membuat program, serta banyaknya downloader yang sesuai dengan bahasa $\mathrm{C}$.

Untuk menguji komunikasi antara mikrokontroler dengan komputer melalui jalur serial maka Mikrokontroler akan mengirimkan suatu data string kemudian akan dikirimkan melalui jalur TX-serial kemudian laptop akan menerima data tersebut melalui jalur RX-serial pada USB port.

Halaman Web JRRE : http://jurnalnasional.ump.ac.id/index.php/JRRE 


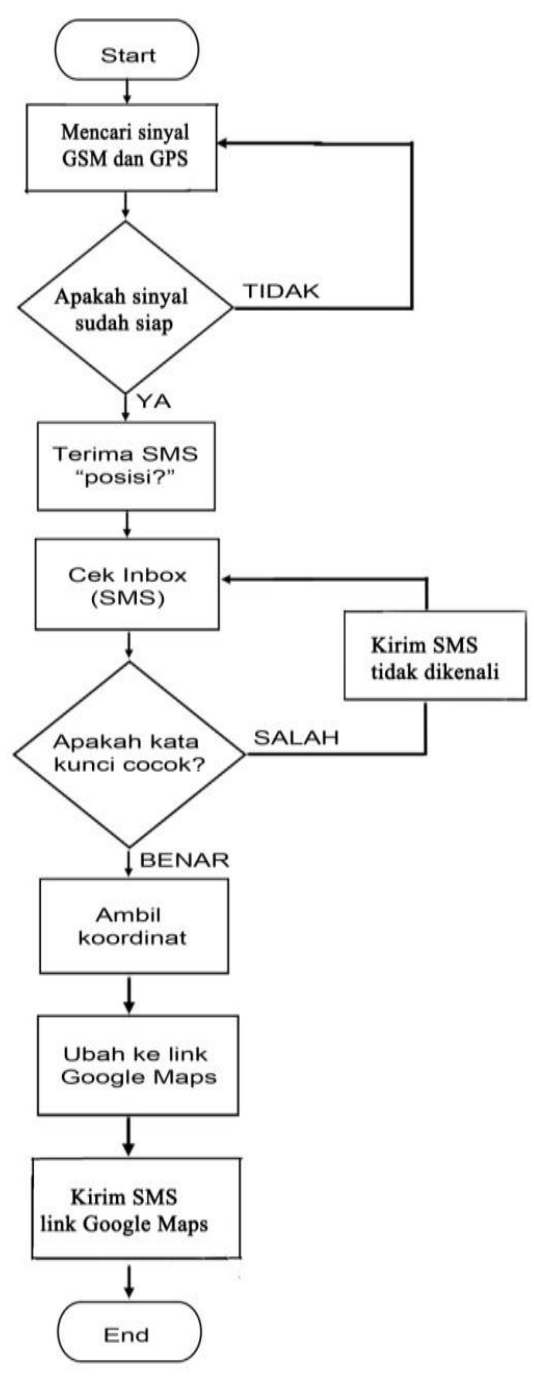

Gambar 3.2 Flowchart sistem GPS

\subsection{Konsumsi Daya Pada GPS Tracker}

1. Kapasitas Baterai

Diketahui Tegangan pada baterai $6,47 \mathrm{~V}$ dengan arus 4,5 A maka:

$\mathrm{P}=\mathrm{V} \times \mathrm{I}$

$=6,47 \times 4,5=29,11$ Watt-Hours

Artinya dalam 1 jam baterai ini dapat menyuplai 29,11 Watt.

2. Penggunaan maksimal alat

Dengan tegangan $5 \mathrm{~V}$ dan arus 0,5 A maka beban yang didapat 2,5 Watt.

Jadi $\mathrm{I}=2,5: 6,47=0,38$ Ampere

Waktu pemakaian $=4,5: 0,38=11,84 \mathrm{Jam}$ 
3. Penggunaan minimal alat

Dengan tegangan $5 \mathrm{~V}$ dan arus $2 \mathrm{~A}$ maka beban yang didapat $10 \mathrm{Watt}$.

Jadi $\mathrm{I}=10: 6,47=1,54$ Ampere

Waktu pemakaian $=4,5: 1,54=2,92 \mathrm{Jam}$

\subsection{Pengujian Program GPS Tracker}

Pengujian ini dilakukan setelah semua rangkaian atau komponen seperti modul GPS, sistem minimum, board arduino, adaptor dan PC telah bekerja dengan baik sesuai yang dibutuhkan. Untuk pengujian alat ini hubungkan setiap komponen sama halnya saat pengujian SMS maupun GPS. Ketik program pada aplikasi Arduino yang ada di PC atau laptop setelah itu upload program

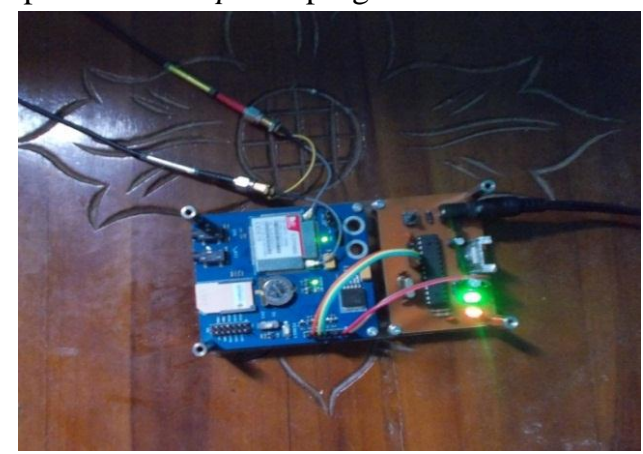

Gambar 3.3 Alat GPS tracker yang siap digunakan

Tabel 3.1. Pengujian alat GPS ketika digunakan pada kendaraan yang sedang berjalan

\begin{tabular}{ccccc}
\hline No & Waktu & Bujur & Lintang & $\begin{array}{c}\text { Penerimaan } \\
\text { SMS }\end{array}$ \\
\hline 1 & $10: 12$ & 109.2729365 & -7.4132084 & 06,72 Detik \\
\hline 2 & $10: 46$ & 109.2976257 & -7.5044797 & 06,32 Detik \\
\hline 3 & $11: 25$ & 109.2566489 & -7.4196963 & 07,11 Detik \\
\hline 4 & $11: 38$ & 109.2691522 & -74392779 & 06,80 Detik \\
\hline 5 & $14: 29$ & 109.1768816 & -7.5370188 & 06,41 Detik
\end{tabular}

Pada Tabel 3.1 pengujian nomor 1 dilakukan ketika kendaraan berjalan di depan masjid Ahmad Dahlan UMP. Pengujian nomor 2 dilakukan di sekitar jembatan Kaliori, Banyumas. Kemudian untuk nilai bujur dan lintang yang didapatkan pada pengujian nomor 3 dilakukan di sekitar SPBU Arca,setelah itu pengujian nomor empat dilakukan didepan RS.Margono. Dan yang terakhir untuk pengujian pada nomor 5 dilakukan di SPBU Rawalo. Untuk pengujian pada alat ketika seadang berjalan didapatkan tunda penerimaan yang tidak jauh berbeda saat alat dalam keadaan diam yaitu dengan tunda penerimaan kurang lebih 6 detik. 


\section{KESIMPULAN}

Dari hasil pengamatan dan pengujian dapat diambil kesimpulan sebagai berikut:

1. Alat pencari posisi kendaraan ini dapat menampilkan posisi kendaraan disuatu tempat menggunakan aplikasi Google Maps.

2. Mikrokontroler AT-Mega 328 dapat mengambil data GPS dan bertukar data pada modul SIM908 menggunakan komunikasi serial TTL.

3. Mikrokontroler AT-Mega328 dapat terhubung dengan server menggunakan komunikasi GPRS melalui perantara modul GSM SIM908.

4. Lokasi koordinat dapat dilihat pada Aplikasi Google Maps setelah didapatkan bujur dan lintang lalu dikonversi kedalam link Google Maps.

5. Penggunaan kartu Telkomsel paling baik karena SMS yang dikirim dapat terkirim dan menerima balasan sedangkan penggunaan kartu IM3 dan XL Axiata SMS yang dikirim selalu tunda.

6. Pada antena GPS keadaan diluar ruangan dan didalam ruangan sangat mempengaruhi antena untuk mencari sinyal GPS, keadaan diluar ruangan lebih cepat untuk menangkap sinyal GPS.

7. Berdasarkan pengujian pencarian poisisi kendaraan didapatkan toleransi maksimal 20 meter dari posisi sebenarnya

\section{DAFTAR PUSTAKA}

[1] Ananta, A.B. 2014. Pengertian UART. Palembang. Politejnik Negeri Sriwijaya adamboga.blogspot.com/2014/04/pengertian-uart.html. Diakses Pada Tanggal 20 Desesmber Jam 19:44 WIB.

[2] Ardiansyah, N. 2015. Rancang Bangun PH Meter Air Di Utilities Refinery Unit IV Cilacap PT PERTAMINA (PERSERO) Berbasis Arduino Uno R3. Skripsi. Universitas Muhammadiyah Purwokerto.

[3] Kuswanto, H. 2015. Sistem Proteksi Kendaraan Bermotor Menggunakan Android Berbasis Mikrokontroller Atmega328. Tangerang. STMIK RAHARJA.

[4] Rifae, A. 2013. Jurnal. Sistem Informasi Pemantau Posisi Kerndaraan Dinas Unsri Menggunakan Teknologi GPS. http://ejournal.unsri.ac.id/index.php/jsi/index. Diakses Pada Tanggal 05 Oktober 2015 Jam 19:43 WIB.

[5] Setiyono. 2014. Rancang Bangun Robot Terbang Dengan 4 Baling-baling (QUADCOPTER) Menggunakan Teknik PWM. Skripsi. Universitas Muhammadiyah Purwokerto.

[6] Susilo,Y.S. dan Hartono Pranjoto. 2014. Jurnal IImiah Widya Teknik. Sistem Pelacakan Dan Pengamanan Kendaraan Bermotor Berbasis GPS Menggunakan Komunikasi GPRS. Surabaya. Universitas Katolik Widya Mandala.teknikelektronika.com > Komponen Elektronika Diakses Pada Tanggal 12 November 2015 Jam 11:06 WIB.

[7] Nurcahyokun.blogspot.com/cara-kerja-komunikasi-usart-dan-uart.htm Diakses Pada Tanggal 19 November 2015 jam 15:30 WIB

[8] http://tutordaninfogoblog.blogspot.com/2013/02/informasi-perintah-at-command.html. Diakses Pada Tanggal 19 November jam 14:03

[9] www.dfrobot.com/.../SIM908_AT\%20Command\%20Manual_V1.01.pdf. Diakses Pada Tanggal 19 November 2015 jam 15:51 WIB.

[10] www.mandalamaya.com > Kamus Populer Diakses Pada Tanggal 08 Desember 2015 jam 21:24 WIB

[11] https://id.wikipedia.org/wiki/GPRS Diakses Pada Tanggal 08 Desember jam 21:40 WIB

Halaman Web JRRE : http://jurnalnasional.ump.ac.id/index.php/JRRE 